\title{
Two Dimension Numerical Simulation on the Aerodynamic Characteristic of Train Running Under the Gust
}

\author{
Jianbin Luo ${ }^{1,}$, Liang $\mathrm{Wu}^{1, \mathrm{~b}}$, Feng Jiang ${ }^{1, c}$ \\ ${ }^{1}$ Automotive and Transportation Engineering Institute, Guangxi University of Science and \\ Technology, Liuzhou 545006, China \\ adilimike168@163.com, bwzhfb168@163.com, 'paperpu168@163.com
}

\begin{abstract}
Keywords: Gust, high speed train, aerodynamic characteristic, numerical simulation.
Abstract: During recent years, with the rapid development of high speed railway construction and the largely improved train speed, its aerodynamic problem has been paid more and more attention to. Particularly under the gust, the train running conditions are deteriorated further so that the safe operation faces the serious challenge. In this paper, the two-dimension computing fluid dynamics numerical simulation on its aerodynamic characteristic has been made about the high speed train running on double line viaduct in the windward under the gust. The simulation results show that there is obvious gust effect when the acceleration is changed for loading side linear wind spectrum. The transverse gust will have distinct influence on the side force, while it is relatively weak for the lifting force. The numerical simulation computing method has been explored by two-dimension field calculation and it can offer the engineering reference for succeeding three-dimension numeration.
\end{abstract}

\section{Introduction}

The high-speed train is often attacked by the gust varying at any time. In Japan, both Zhufei line accident in 1998 and Rifeng line accident in 2006 are thought of as being caused by the gust [1,2]. The side wind security problem of high-speed train is paid more and more attention to by domestic and oversea researcher. A series of experimental and numerical research work has been already launched on it. But in the past researches, the side wind is supposed to be distributed uniformly and does not be considered its time non-uniformity. So, the actual train running conditions under the natural wind environment will be reproduced really only properly taking into account time heterogeneity of the side wind. In order to probe into gust impact on aerodynamic characteristic of train, it has been simplified as two-dimension situation along the symmetrical cross section of train. On one hand, calculation consumption and cost may be reduced greatly. On the other hand, the two-dimension simulation may become its advanced research and lay the foundation for three-dimension calculation.

\section{Theoretical and Computing Model}

In the numerical simulation, the air stream is regarded as a two-dimensional, isentropic, incompressible, unsteady and viscous flow system. In addition, the realizable $k-\varepsilon$ turbulence model is selected. So, the solved equations include continuum equation, momentum equation, turbulent kinetic energy and dissipation rate equations[3].

For the side wind velocity $V_{z}$, both space exponential distribution and time non-uniformity are considered in the simulation and its direction is perpendicular to the longitudinal symmetric cross section of the train. Its mathematical expression is shown as following.

$$
\begin{aligned}
V_{z} & =\left(\frac{z}{z_{s}}\right)^{\alpha} * V_{z s} \\
V_{z s} & =\left\{\begin{array}{lc}
20, & t \leq 0.5 \\
25 * t+7.5, & 0.5 \leq t \leq 0.9 \\
30, & 0.9 \leq t \leq 1.1
\end{array}\right.
\end{aligned}
$$


Here, $V_{z}(\mathrm{~m} / \mathrm{s})$ represents the wind speed in the height of $\mathrm{z}, z(\mathrm{~m})$ is the vertical height, $z_{s}$ is equal to $1.0 \mathrm{~m}$ as the reference height, $V_{z s}(\mathrm{~m} / \mathrm{s})$ indicates the wind speed in the reference height of $z_{s}$ and $\mathrm{t}$ (s) is the flow time. The $\alpha$ indicates the earth's surface roughness influence coefficient and it is given to 0.16 considering the second type of earth's surface.

The scale model(1: 10) is used in the numerical simulation. The height is $1.5 \mathrm{~m}$ from the viaduct bottom surface to ground and the height of sound barrier is $0.3 \mathrm{~m}$. The train is situated in the windward[4] and the distance is equal to $0.37 \mathrm{~m}$ and $0.87 \mathrm{~m}$ respectively from train longitudinal centre line to the left side or right side of the sound barrier. The discrete mesh in the flow domain is shown in Fig. 1.

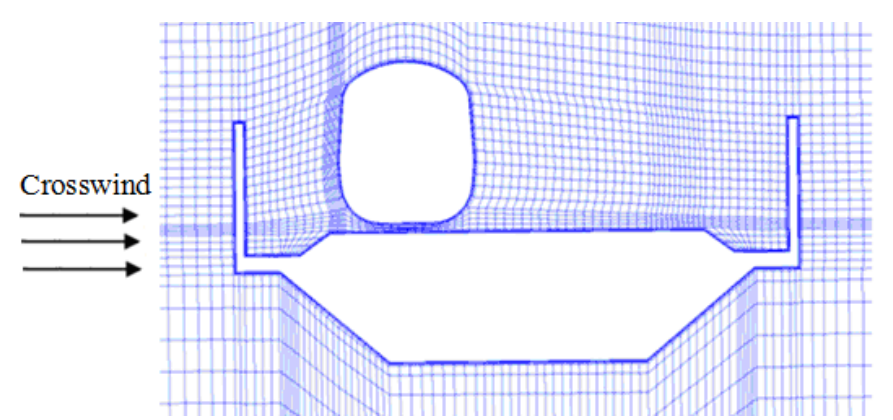

Fig.1 Computing grid near train body and viaduct

In the flowing area, the velocity inlet and pressure outlet are given. All surfaces such as ground, train body and viaduct are set for non-slip stationary wall boundary. The symmetric boundary is selected on the roof because the whole computing region is so large that top surface hardly has influence on the flowing field. The control equations are dispersed by the finite volume method and solved using the method based on the pressure. The algorithm of Semi-Implicit Method for Pressure-Linked Equations Consistent(SIMPLEC) is adopted when coupled pressure and velocity $[5,6,7,8]$.

In order to confirm the appropriate time step, the comparison of train aerodynamic force or moment coefficient is provided under three kinds of different time steps in the Fig.2 and 3. The gust effect can be found from the calculation results under three kinds of time steps. The relative variation aerodynamic force or moment coefficient is quite different for $0.5 \mathrm{~s}-0.502 \mathrm{~s}$ and is near for $0.502 \mathrm{~s}-0.503 \mathrm{~s}, 0.9 \mathrm{~s}-0.902 \mathrm{~s}$ and $0.902 \mathrm{~s}-0.903 \mathrm{~s}$. With the increasing of the time step, the gust effect will be overestimated a little. Considering comprehensively computational effect and precision, the time step of unsteady calculation is finally determined to $0.001 \mathrm{~s}$.

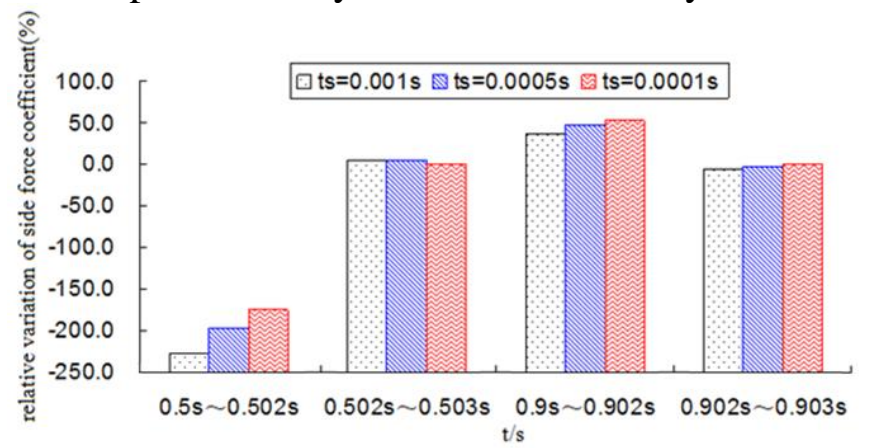

a. side force coefficient

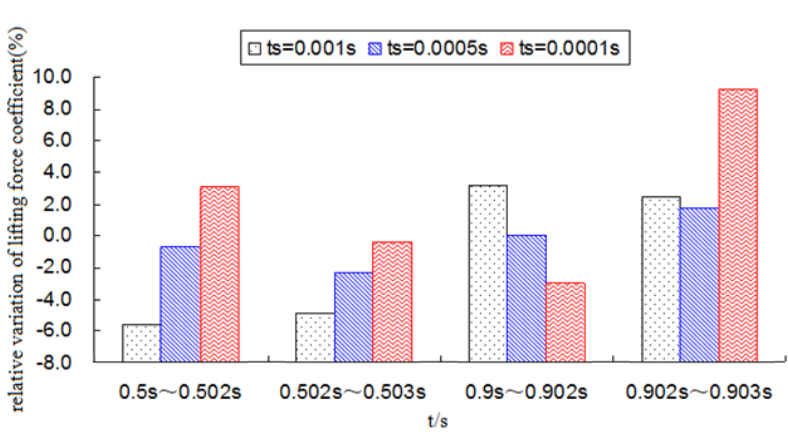

b. lifting force coefficient

Fig. 2 Variation of aerodynamic force coefficient on the train body 


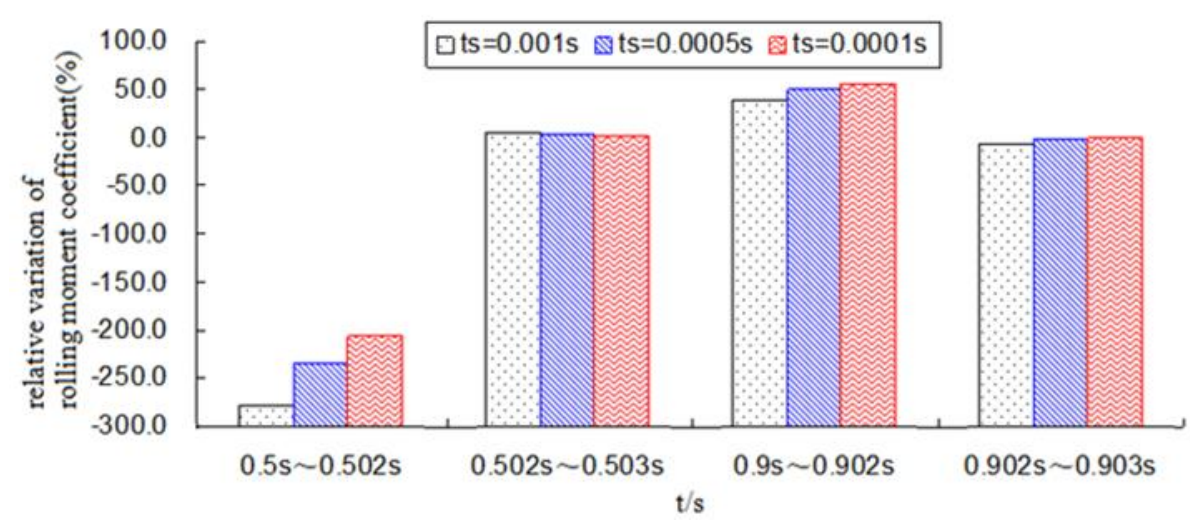

Fig.3 Variation of rolling moment coefficient on the train body

\section{Computing Result Analysis}

When computing the aerodynamic force or moment coefficient the train height $0.361 \mathrm{~m}$ is selected as the characteristic length, the reference area is $0.361 \mathrm{~m}^{2}$, the reference speed is $20 \mathrm{~m} / \mathrm{s}$, the atmospheric density is $1.225 \mathrm{~kg} / \mathrm{m}^{3}$ and the reference pressure is $1.013 \times 10^{5} \mathrm{~Pa}$.

The aerodynamic force or moment coefficient changing law of the train body can be seen from Fig. 4 and 5. At the time of $\mathrm{t}=0.5 \mathrm{~s}$ (starting acceleration) or $\mathrm{t}=0.9 \mathrm{~s}$ (transforming to constant speed), the side force and rolling moment coefficients are suddenly increased while the lifting coefficient does not. Especially for the side force coefficient, the relative variation value is $228.1 \%$ between $\mathrm{t}=0.5 \mathrm{~s}$ and $\mathrm{t}=0.502 \mathrm{~s}$ and is only $4.6 \%$ between $\mathrm{t}=0.502 \mathrm{~s}$ and $\mathrm{t}=0.503 \mathrm{~s}$. While for the lifting force coefficient, the relative variation value is less than $10 \%$ between $\mathrm{t}=0.5 \mathrm{~s}$ and $\mathrm{t}=0.502 \mathrm{~s}$ or between $\mathrm{t}=0.502 \mathrm{~s}$ and $\mathrm{t}=0.503 \mathrm{~s}$. For the rolling moment coefficient, the same variation law is revealed that the relative variation value is $277.92 \%$ between $t=0.5 \mathrm{~s}$ and $\mathrm{t}=0.502 \mathrm{~s}$ and is only $4.08 \%$ between $\mathrm{t}=0.502 \mathrm{~s}$ and $\mathrm{t}=0.503 \mathrm{~s}$.

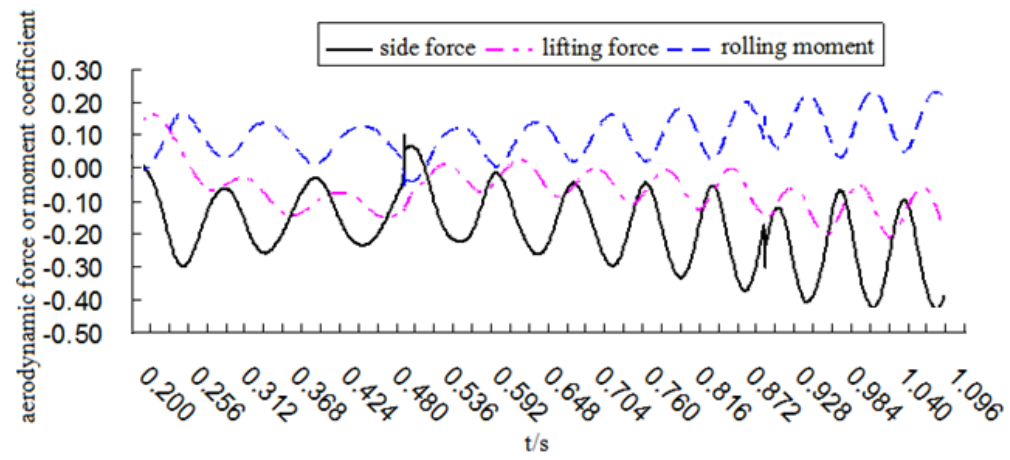

Fig.4 Time histories of aerodynamic force or moment coefficient

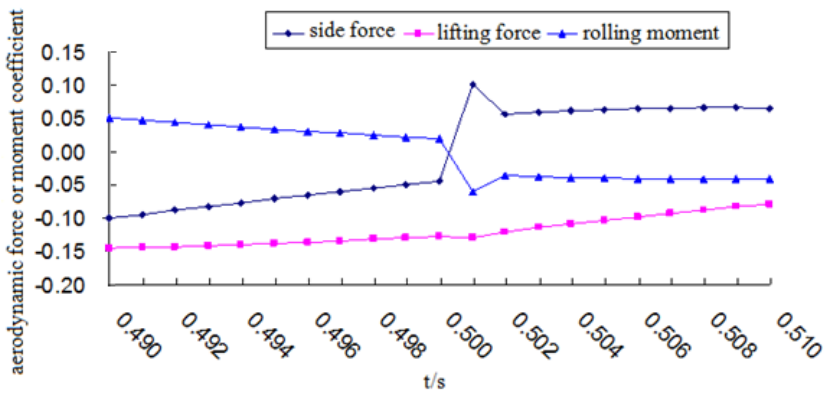

a. $\mathrm{t}=0.49 \mathrm{~s}-0.51 \mathrm{~s}$

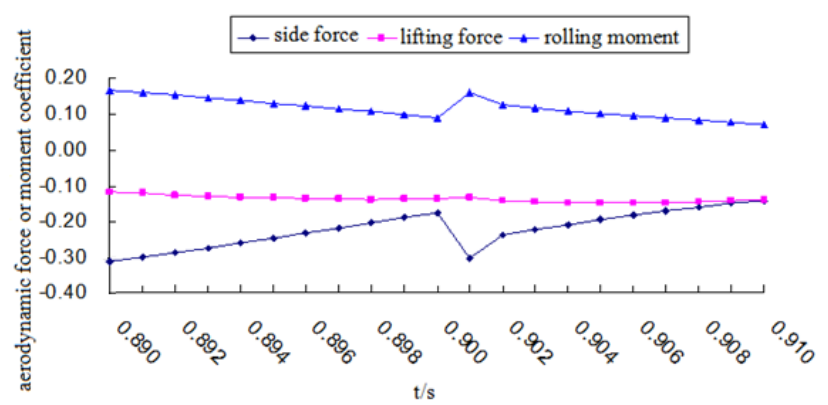

b. $\mathrm{t}=0.89 \mathrm{~s}-0.91 \mathrm{~s}$

Fig. 5 Time histories of aerodynamic force or moment coefficient

From Fig. 6 the static pressure coefficient of measured point in the flow field can be partially analyzed and then the altering law of aerodynamic coefficient can be partially explained. The changing tendency of the instantaneous speed and static pressure coefficient can be shown from Fig.7 
and 8 respectively. It can be seen that the instantaneous velocity is varied continuously in Fig.7. While it can be displayed that the static pressure coefficient at $\mathrm{t}=0.5 \mathrm{~s}$ and $\mathrm{t}=09 \mathrm{~s}$ is changed abruptly.

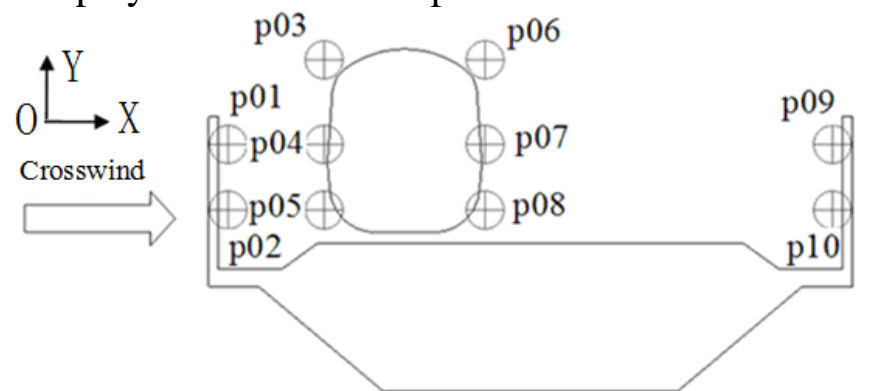

Fig.6 Measured point distribution in flow field

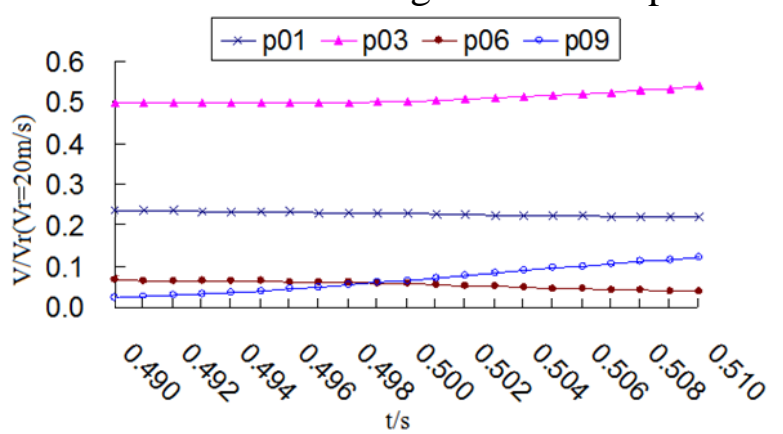

a. $\mathrm{t}=049 \mathrm{~s}-0.51 \mathrm{~s}$

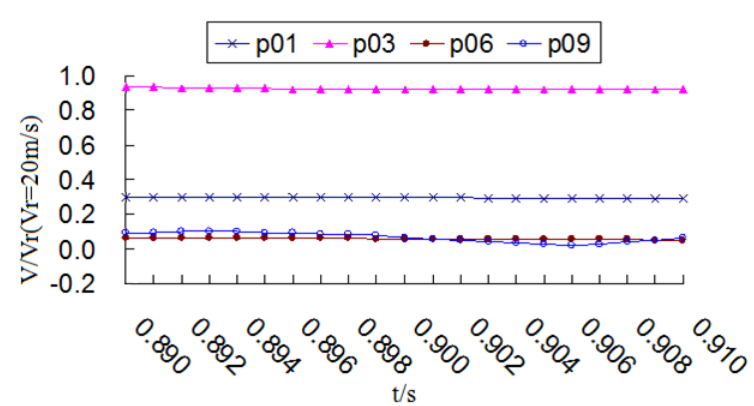

b. $\mathrm{t}=0.89 \mathrm{~s}-0.91 \mathrm{~s}$

Fig.7 Variation with time of instantaneous velocity of measured point in flow field

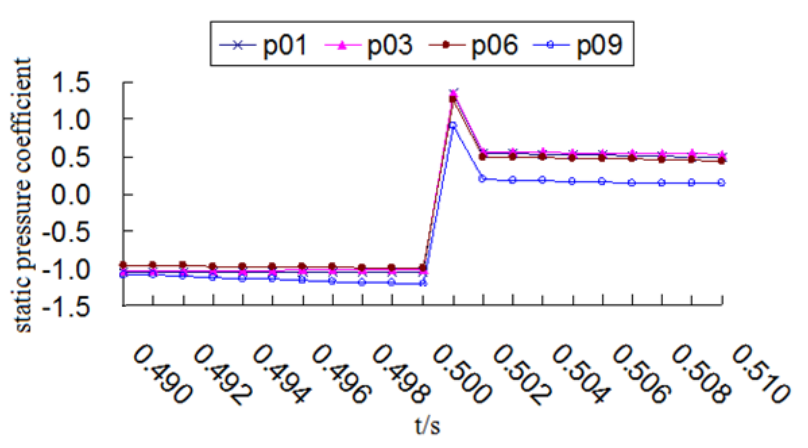

a. $\mathrm{t}=049 \mathrm{~s}-0.51 \mathrm{~s}$

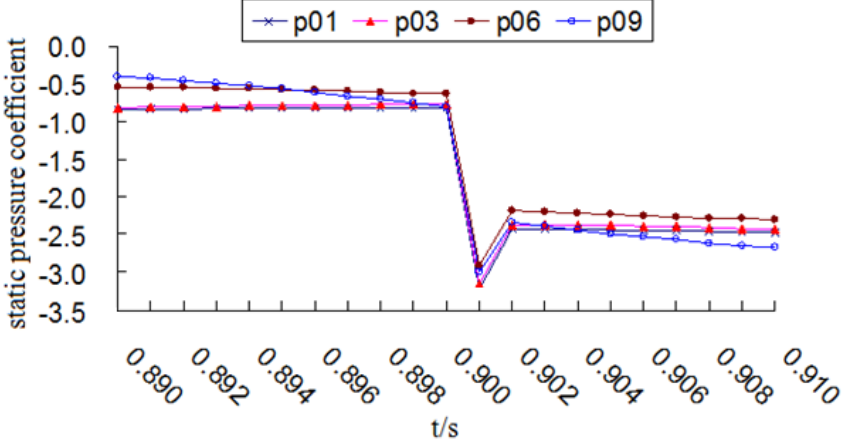

b. $\mathrm{t}=0.89 \mathrm{~s}-0.91 \mathrm{~s}$

Fig. 8 Variation with time of static pressure coefficient of measured point in flow field

The variation law of aerodynamic force or moment coefficient can be explained by analyzing the static pressure coefficient of measured point on train body in Fig.9. The static pressure coefficient on train body varying with time is indicated in Fig.10. It is obvious that the static pressure coefficient on train body is changed so suddenly that it causes the force or moment is altered suddenly between $\mathrm{t}=0.5 \mathrm{~s}$ and $\mathrm{t}=0.502 \mathrm{~s}$ or between $\mathrm{t}=0.9 \mathrm{~s}$ and $\mathrm{t}=0.902 \mathrm{~s}$.

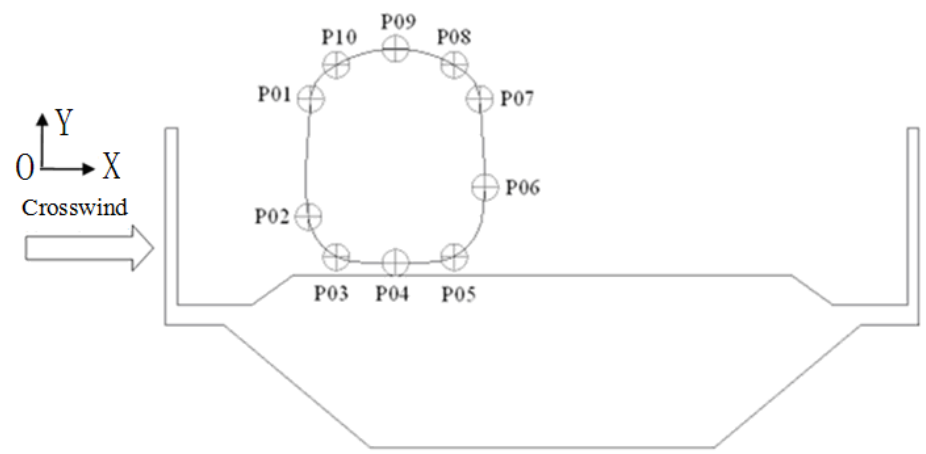

Fig.9 Measured point distribution on the train 


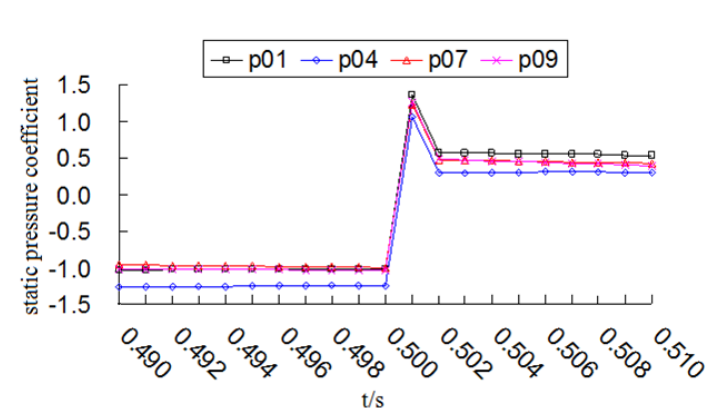

a. $\mathrm{t}=049 \mathrm{~s}-0.51 \mathrm{~s}$

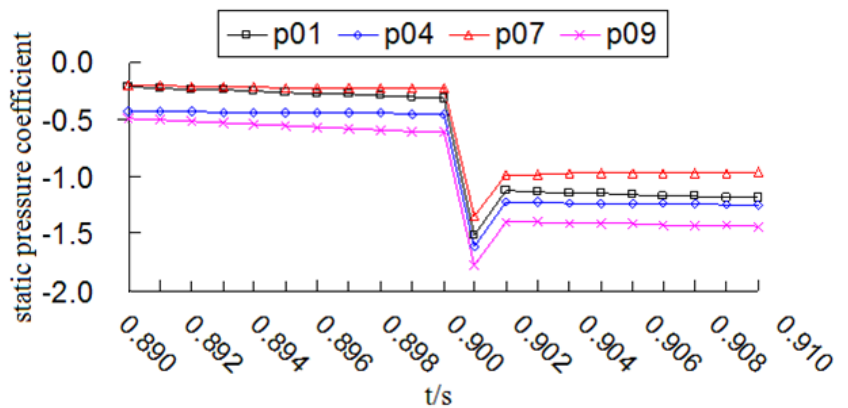

b. $\mathrm{t}=0.89 \mathrm{~s}-0.91 \mathrm{~s}$

Fig.10 Variation with time of static pressure coefficient of measured point on the train

The comparison of static pressure coefficient on the train body between $t=0.5 \mathrm{~s}$ and $\mathrm{t}=0.502 \mathrm{~s}$ or between $\mathrm{t}=0.9 \mathrm{~s}$ and $\mathrm{t}=0.902 \mathrm{~s}$ is indicated respectively in Fig. 11 and 12 . The lifting or side force variation can be concluded from the static pressure coefficient along $\mathrm{x}$ or $\mathrm{y}$ direction accordingly. For the lifting force, the value at $\mathrm{t}=05 \mathrm{~s}$ is near to at $\mathrm{t}=0.502 \mathrm{~s}$, but for side force the value at $\mathrm{t}=0.502 \mathrm{~s}$ is larger than at $=0.5 \mathrm{~s}$. It shows the same varying tendency between $\mathrm{t}=0.9 \mathrm{~s}$ and $\mathrm{t}=0.902 \mathrm{~s}$ that the lifting force is changed a little and the side force is changed largely.

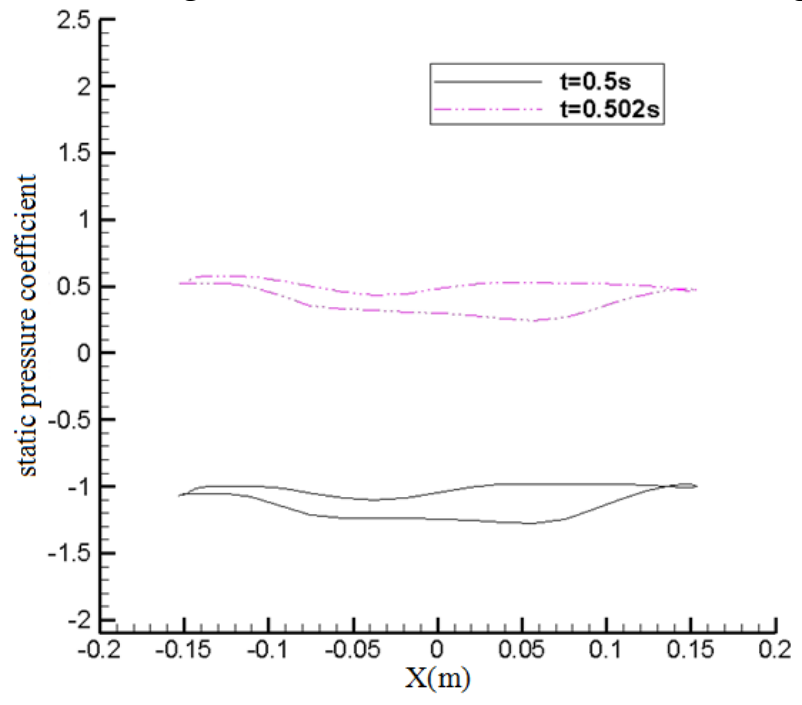

a. along the $\mathrm{x}$ direction

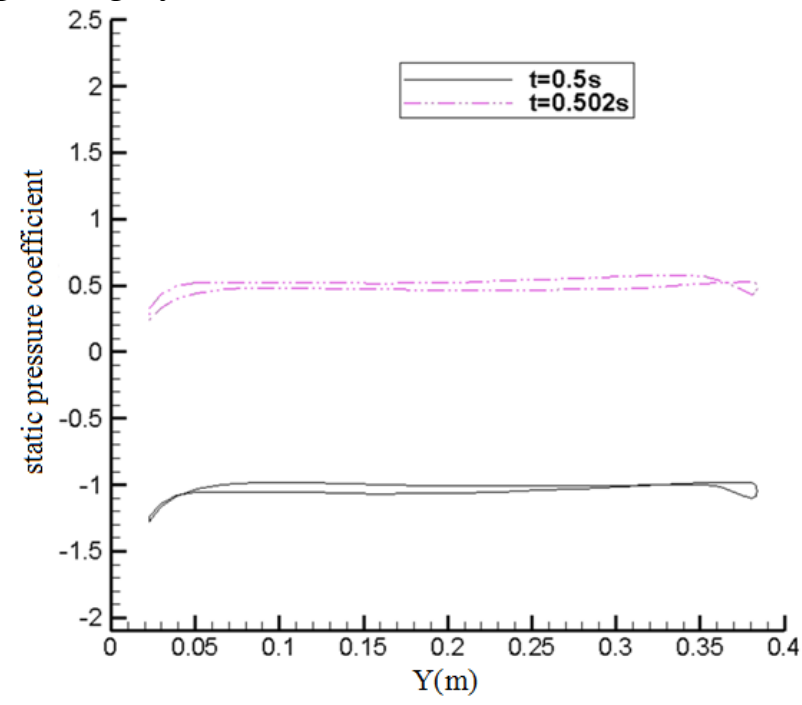

b. along the y direction

Fig.11 Comparison of static pressure coefficient of train body

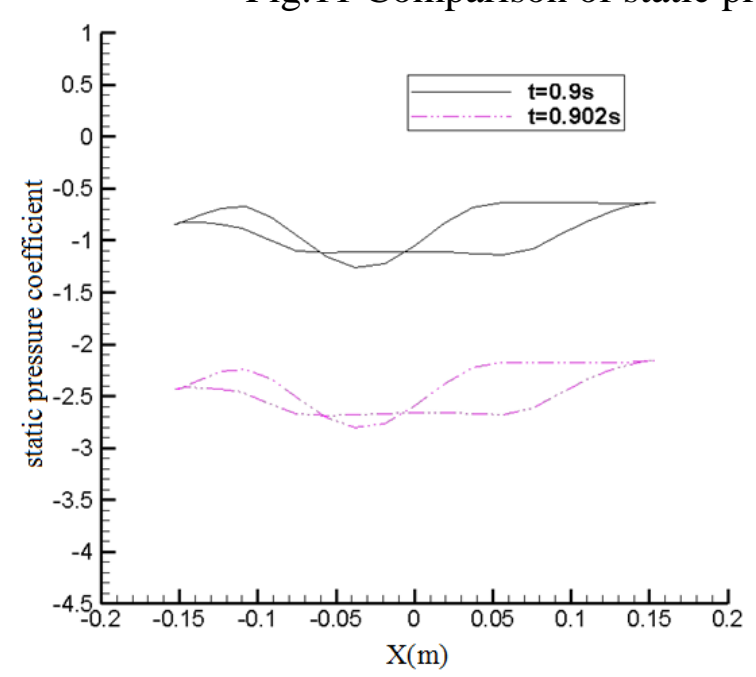

a. along the $\mathrm{x}$ direction

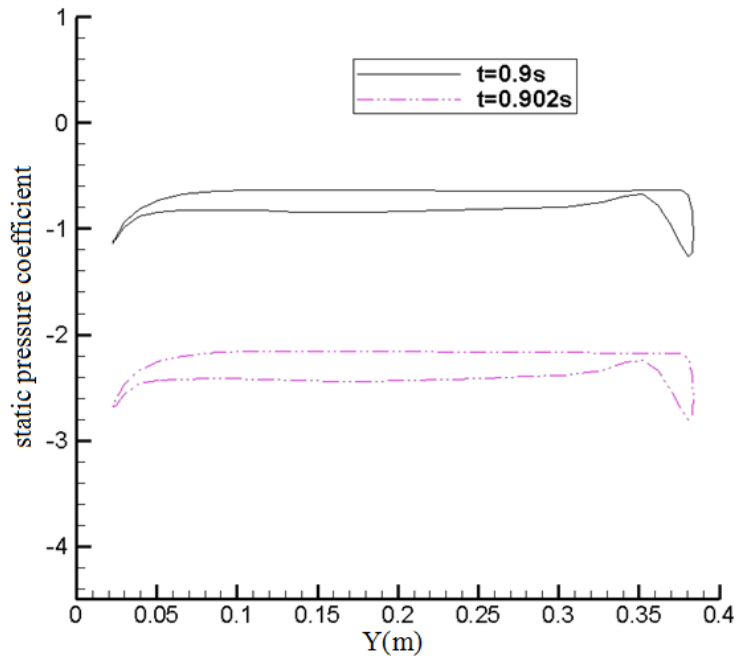

b. along the y direction

Fig.12 Comparison of static pressure coefficient of train body 


\section{Conclusions}

Using the numerical fluid dynamics method, the aerodynamic characteristic of the train has been explored under the linear acceleration side wind. The simulation result indicates that the aerodynamic force behaves to be violently unsteady under overlapping blunt body flow with gust. The aerodynamic force or moment is changed continuously at even acceleration but is changed abruptly when it is converted from constant velocity to uniform acceleration each other. The acceleration in $y$ direction (in the direction of side wind) is loaded on the gust spectrum, so the gust effect affects side force on the whole train body larger than lifting force. The actual running velocity of the train is not considered in the two-dimension calculation, but the numerical simulation computing method can be explored through it and it can also offer the reference for succeeding three-dimension numeration.

\section{Acknowledgments}

This work was financially supported by high school research project of Guangxi department of education(YB2014204), doctoral program of Guangxi institute of technology(Institute doctoral scientific research 13Z10) and the sub-project of Guangxi key laboratory construction(14-A-01-03).

\section{References}

[1] Masataka Fujii, Toshishige Fujii, Hisashi Muraishi. History of railway operational regulation under strong wind condition[R]. Railway Technical Research Institute Report. 1995, 9(3): 43-48.

[2] Matsumoto M, Shimamura M, Maeda T. Drag force on 2-D cylinders due to sudden increase for wind velocity $[\mathrm{C}]$. Proceedings of the 12th International Conference on Wind Engineering. Cairns, Australia, 2007:727-734.

[3] Fujun Wang. Computational fluid dynamics analysis[M].Peking: Tsinghua university press, 2006:7-130.

[4] Pindado S, Meseguer J, Franchini S. The Influence of the section shape of box-girder decks on the steady aerodynamic yawing moment of double cantilever bridges under construction[J]. Journal of Wind Engineering and Industrial Aerodynamics,2005,9(3):547-555.

[5] Jianbin Luo, Aijun Hu. Numerical study of the effect of viaduct noise barrier height on train aerodynamic characteristics[J].Chinese journal of computational physics,2012,29(1):65-72.

[6] Jianbin Luo, Yuanyuan Hu, Jianheng Yang, Aijun Hu. Effect of embankment inclining angle on aerodynamic characteristics of high speed train under crosswinds[J]. Chinese journal of computational physics,2013,30(5):675-682.

[7] Jianbin Luo, Aijun Hu, Tengchao Su. Numerical study on influence of noise barrier height on aerodynamic characteristics of train[J]. Journal of Guangxi university of science and technology,2014,25(3):14-19.

[8] Jianbin Luo, Aijun Hu. Effect of running environment on the aerodynamic characteristic of high speed train under the crosswind $[\mathrm{J}]$. Journal of Guangxi university of science and technology,2016,27(1):1-5. 